\title{
DE TOLÓN A TRAFALGAR: LAS OPERACIONES DE LA ESCUADRA COMBINADA A TRAVÉS DE LA GACETA DE MADRID
}

\author{
ANTonio VAliente Romero \\ Lourdes Márquez Carmona \\ Centro de Arqueología Subacuática. \\ Instituto Andaluz del Patrimonio Histórico
}

\section{RESUMEN}

Se analizan los sucesos acontecidos los meses anteriores al combate naval de Trafalgar, librado el 21 de octubre de 1805 entre la Escuadra Inglesa de un bando y la Escuadra Hispano-francesa de otro, a través de la Gaceta de Madrid, elemento de la cultura escrita imbricada en la gestión política de España en el tránsito entre el Antiguo y Nuevo Régimen.

Palabras claves: batalla de Trafalgar, guerras napoleónicas, prensa oficial, Gaceta de Madrid.

\section{ABSTRACT}

The events occurred in the months prior to the naval battle of Trafalgar, which took place on 21 October 1805 between the English fleet on one hand and the Franco-Spanish one on the other, are analysed in the Gazette of Madrid, vehicle for written culture on the political management in Spain during the transition from Ancient Regime to New Regime.

Key words: battle of Trafalgar, Napoleonic Wars, official gazzete, Gaceta de Madrid. 


\section{INTRODUCCIÓN}

La Gaceta de Madrid fue concebida como el órgano de comunicación y opinión propio de la Monarquía Española durante el siglo XVIII. Se trata de la puesta en práctica de las nuevas ideas respecto a la opinión pública y control de la información. Sin embargo, no podemos considerar que se trate de un instrumento aislado sino imbricado dentro de la política ilustrada propugnada por el reformismo borbónico. De esta forma se configura una nueva forma de hacer política que dejando atrás las viejas ideas imperiales prestará especial atención a la realidad política y económica del país.

La Gaceta se integra dentro del conjunto de instrumentos que inaugurarán en España los nuevos estadistas. Entre ellos se encuentra un incipiente intento de control de la opinión pública (Gaceta de Madrid), el nacimiento en España de la estadística aplicada a la política y la economía (catastro del Marqués de la Ensenada) etc. Todos estos instrumentos formarán parte de una nueva mentalidad ilustrada que caracterizará la política española del siglo XVIII.

A pesar de que muchos de los avatares políticos y económicos, tanto del país como de Europa, hicieron que esta política no diese todos los resultados esperados, sus instrumentos se demostraron altamente útiles, hasta el punto de sobrevivir a la misma política que los creó, llegando muy transformados hasta nuestros días, en el caso de la Gaceta, convertida en el actual Boletín Oficial del Estado. A lo largo del presente trabajo realizaremos un estudio de la Gaceta de Madrid como elemento de la cultura escrita imbricada en la gestión política del país en el tránsito entre el Antiguo y Nuevo Régimen, tomando para ello como hilo conductor los sucesos acontecidos los meses anteriores al combate naval de Trafalgar, librado el 21 de octubre de 1805 entre la Escuadra Inglesa de un bando y la Hispano-Francesa de otro.

\section{EVOLUCIÓN DE LA GACETA DE MADRID: DE LOS ORÍGENES A 1805}

El origen de la Gaceta de Madrid es bastante confuso, ya que proviene de las relaciones y folletos de índole político o anecdótico que se habían dado en España ya desde el siglo XVI, y en varias repúblicas italianas con antelación.

En nuestra opinión, consideramos que bajo el título: Gaceta Nueva de las cosas más particulares, así políticas como militares sucedidas en la mayor parte de la Europa, hasta el mes de febrero de este año de mil y seiscientos y sesenta y uno, se publica el primer ejemplar de lo que podemos considerar el antecedente de la Gaceta de Madrid. Ésta a su vez se editaba por parte de imprentas privadas, pudiéndose leer en la portada del mismo ejemplar: con licencia en Madrid, por Julián de Paredes impresor de libros en la plazuela del Ángel, año de $1661^{1}$.

La publicación de este ejemplar marcará el inicio de una serie de fases evolutivas por las que pasará la publicación hasta llegar a convertirse en el órgano de control de la opinión pública de que hemos hablado. Con anterioridad, en España se imprimen folletos de opinión política y noticias a imitación de las gacetas italianas. A partir de la fecha señalada, se inicia la andadura de la gaceta como tal, si bien con una evolución llena de vicisitudes que culminará con su prohibición en el año 1680. Esta prohibición implica una vuelta atrás, ya que se impide la publicación de un periódico de opinión política especializado, si bien los folletos privados anteriormente mencionados, que habían coexistido paralelamente a la impresión de la gaceta,

Gaceta de Madrid (01-01-1860), p. 4.

Con objeto de facilitar la comprensión de la intencionalidad de los textos de la Gaceta, en el presente trabajo hemos actualizado la ortografía de las citas textuales. 
vuelven a expandirse ya que la prohibición no les afecta. Finalmente, será en 1725 cuando reaparezca la Gaceta de Madrid ya como órgano oficial de expresión de la Monarquía y con este mismo título².

La publicación surgida a principios del siglo XVIII mantiene inmutable la estructura y contenido de la etapa anterior. En reglas generales, cuenta con un primer apartado con las noticias de Viena, seguido de otro con las de Génova, Londres, La Haya, París y finalmente Madrid ${ }^{3}$. Por otra parte, cuenta con una sección que podríamos denominar bibliográfica. Ésta se sitúa al final y en ella se reseñan, con mas o menos detalle según el caso, las obras editadas por la Imprenta Real.

Dentro de la estructura de la Gaceta, en función a los sucesos políticos tenidos lugar en Europa, se insertaban las noticias de otros lugares diferentes, basándose en la importancia de las mismas para la Monarquía.

Durante esta época, tan sólo se constata en la Gaceta el tratamiento de acontecimientos o situaciones políticas y militares de otros países de Europa, mientras que respecto a España en ningún momento se constatan situaciones o hechos que no sean consumados, y estos últimos tan sólo en caso de que el resultado de dichos hechos o acciones sea favorable a la Monarquía absoluta. Se trata, evidentemente, de un sistema bastante arcaico de polarización de la opinión pública a favor del Régimen. Ante este razonamiento, podría aducirse que un sistema político como la monarquía absoluta del siglo XVIII, basada en el despotismo ilustrado, no tenía necesidad de un sistema de tales características. Esto nos lleva a considerar el momento en que, tras la prohibición anterior, resurge la Gaceta de Madrid, esta vez con apoyo oficial, como hemos dicho, a principios del siglo XVIII (1725), momento en que ya empieza a correr por Europa el embrión de las ideas ilustradas que desembocarán en la Revolución Francesa. De esta forma, la monarquía utiliza la polarización de la opinión pública a su favor como un método más para frenar el empuje de las ideas revolucionarias.

Dentro de esta dinámica, presentan una ocasión inmejorable los hechos acaecidos con anterioridad a la batalla naval de Trafalgar para llevar a cabo el análisis del funcionamiento de la Gaceta de Madrid como órgano de información de la Monarquía Española e incipiente sistema de control de las mentalidades. La elección de tales hechos para la realización de nuestro análisis práctico no viene en medida alguna dada por el azar o el mayor o menor atractivo que puedan plantear los movimientos de la Escuadra Combinada franco-española, sino porque plantean una coyuntura excepcional para su realización debido a una serie de razones:

En primer lugar, en el ámbito cronológico nos encontramos en el momento de mayor madurez de la Gaceta como sistema de información estatal propio de la monarquía del Antiguo Régimen, llegando pocos años después, en $1809^{4}$, un segundo estadio en la evolución de la Gaceta de Madrid, caracterizado por la difusión de la política española en forma de decretos, órdenes etc., estableciéndose aquí la línea divisoria entre la Gaceta del Antiguo y del Nuevo Régimen.

Por otra parte, se trata de una serie de hechos en los que, como veremos, la posición del órgano que gestiona la información pasa por diversas coyunturas, desde el secretismo, pasando por el intento de la difusión de un supuesto éxito, hasta la confusión y, finalmente, la inevitable confirmación de la derrota.

Finalmente, la participación en los hechos de los Estados de Francia e Inglaterra permite observar la utilización que de la información proporcionada respecto a unos mismos hechos por los medios de información de tales naciones hace la Gaceta.

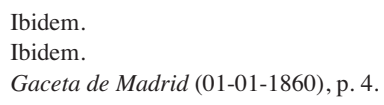




\section{SILENCIO Y RUMORES: LA SINGLADURA DE LA ESCUADRA COMBINADA}

Ya desde la Guerra de Sucesión, las dos grandes potencias marítimas de la Edad Moderna, Inglaterra y España, inician una serie de maniobras militares y acciones políticas que a lo largo de todo el siglo XVIII esbozarán el camino hacia un enfrentamiento por el control del Océano, que se materializará finalmente en el combate naval de Trafalgar. La cuestión se había hecho tan evidente, que algún autor ha llegado a considerar que ...pocas veces dos naciones han tenido mas motivos inmediatos para guerrear ${ }^{5}$.

En el camino hacia dicho acontecimiento, el vertiginoso ascenso del poder napoleónico en Europa, unido a los Pactos de Familia que España mantenía con Francia, actuaron como un poderoso catalizador que aceleró los acontecimientos y pronto produjo el desencadenamiento de la guerra y la consecuente unión de las fuerzas marítimas franco-españolas, dando lugar a la Escuadra Combinada.

Sobre el papel, podemos decir que los orígenes de la Escuadra Combinada Franco-Española, bajo mando militar francés, se encuentra en la firma entre ambas naciones del Tratado de Subsidios en 1803, por el cual España prestaba su ayuda económica a Francia frente a Inglaterra. Esta situación provocó necesariamente un continuo hostigamiento de las unidades navales españolas por parte de las inglesas, ambiente de hostilidad que culminaría finalmente con la declaración de guerra de España a Inglaterra en diciembre de $1804^{6}$. Sin embargo, su origen en la práctica se encuentra en la salida del almirante Villeneuve el 30 de Marzo de 1805 del puerto de Tolón al mando de una escuadra de once navíos de línea que, tras una pequeña maniobra de distracción a la escuadra de Nelson, entró en el puerto de Cádiz el 9 de abril, donde, siguiendo órdenes específicas de Godoy, le aguardaba el almirante Gravina con seis navíos de línea dispuestos para partir.

Esta serie de acontecimientos respondía al plan trazado por Napoleón para la invasión de Inglaterra, dentro del cual la maniobra a ejecutar finalmente por la Escuadra Combinada consistiría en la realización de una nueva serie de maniobras de distracción que alejase del canal de la Mancha a la flota inglesa, de forma que el camino quedase expedito para el desembarco del ejercito francés en la isla ${ }^{7}$. Dicho plan, en lo que respecta al papel que debía realizar la Escuadra Combinada, se articulaba en dos tiempos fundamentalmente: en primer lugar, los navíos franceses y españoles deberían iniciar una singladura atlántica cuyo destino y objetivos habían de permanecer en el más estricto secreto, actuando como señuelo para el grueso de la flota inglesa, bajo las órdenes de Nelson. En un segundo momento, la Escuadra Combinada debía poner de improviso rumbo a Europa para garantizar el desembarco, aun a costa de un enfrentamiento directo con las unidades de la flota inglesa que hubiesen quedado emplazadas en el viejo continente.

La misma noche de la llegada de la escuadra de Villeneuve a las inmediaciones del puerto de Cádiz zarpó la que se encontraba bajo mando de Gravina, uniéndose a la anterior ya bajo mando unificado del almirante francés. La Escuadra Combinada se había formado en la práctica y se iniciaba la singladura por aguas del Atlántico.

En este estado de cosas, y una vez puesto en marcha el ambicioso plan napoleónico, ¿qué papel jugó la Gaceta de Madrid en esta coyuntura como órgano de expresión del Estado Español?

Resulta obvio tras lo ya expuesto que la pieza clave para la consecución de los objetivos de la travesía atlántica era el mantenimiento del más absoluto secreto en cuanto a los objetivos

LON ROMEO, E.: Trafalgar: papeles de la campaña de 1805. Zaragoza, Diputación Provincial de Zaragoza, 1950, p. 23. CAYUELA FERNÁNDEZ, J. et al.: Trafalgar. Hombres y naves entre dos épocas. Barcelona, Ariel, 2004, p. 163.

Ibidem, p. 169. 
de la Escuadra Combinada, con lo cual, decir que la Gaceta guardó al respecto el más absoluto mutismo sería una explicación no del todo cierta y a su vez excesivamente simplista.

Si tomamos la serie de referencias que en la Gaceta de Madrid encontramos respecto a la Escuadra Combinada desde el momento de su formación hasta los últimos meses del año 1805, constatamos la existencia de un total de diecisiete, que se extienden cronológicamente entre el 2 de Julio y el 22 de noviembre de dicho año. En cuanto a la fuente de los datos que se aportan en tales referencias, podemos hacer una división fundamental entre directas e indirectas. Las primeras son textos que aparecen encabezados por el nombre de una población española seguido de la fecha del suceso a que se refieren. Se trata de comunicaciones cuya fuente es el propio Estado, que las da a conocer a través de su propio órgano de expresión. En cuanto a las referencias indirectas, su encabezamiento está formado por el nombre de una capital extranjera seguido de la fecha. En estos casos, suelen ser acontecimientos y noticias que la Gaceta recoge de otros órganos de expresión europeos, en buena parte de las ocasiones sus homónimos extranjeros, tales como The Star, The Traveller, etc.

Hemos dicho con anterioridad que la explicación del mutismo de la Gaceta no es del todo cierta. La razón estriba en que durante la singladura de la Escuadra Combinada no encontramos ninguna referencia directa a la misma, lo cual equivale a decir que el Estado español guardó el mencionado silencio. Sin embargo, encontramos varias referencias indirectas, todas ellas tomadas de fuentes inglesas, tanto a la Escuadra Combinada, como a la de Nelson. Llegados a este punto, sería ingenuo pensar que tales referencias fueron publicadas bajo criterios imparciales, aleatorios o meramente informativos, siendo más lógico pensar que la Gaceta también tuvo su papel dentro de la maquinaria estatal que España puso al servicio de los planes napoleónicos. Un análisis de tales referencias nos puede permitir la reconstrucción, al menos parcial, de la estrategia informativa seguida por la Gaceta mientras la Escuadra Combinada se encontraba al otro lado del Atlántico.

Así, el 9 de Abril de 1805 hizo su entrada en la Bahía de Cádiz el navío francés Aigle, señal convenida para informar de la arribada de la escuadra francesa, que se encontraría ya en las proximidades esperando la unión de las fuerzas españolas de Gravina. Esta forma de actuación confirma que el plan ya expuesto necesitaba para su realización del mayor secreto posible, pues los servicios británicos de información intuían algún importante cambio estratégico en torno al área del canal de la Mancha. De hecho la singladura de las antillas sería conocida por Gravina con muy poca antelación a la partida ${ }^{8}$.

En este estado de cosas, la flota hispano-francesa abandonó el puerto de Cádiz en la noche entre el 9 y 10 de Abril, rumbo hacia el continente americano.

Con bastante posterioridad a la partida de la Escuadra Combinada se produce la primera comunicación indirecta de la Gaceta. Se trata de un texto en el que se intercalan fragmentos entresacados de varios medios de información ingleses, procedentes a su vez de distintas ciudades. Su contenido es casi netamente naval, pero en él se mezclan a su vez referencias a la Escuadra Combinada con otras que mencionan apresamientos por parte de corsarios franceses de varios tipos de embarcaciones inglesas, dando una impresión de conjunto de control del mar por parte de las fuerzas del eje París-Madrid. Esta visión de conjunto se refuerza con la afirmación, acto seguido, por parte de los ingleses de que el comercio que hacíamos en las Indias Occidentales ha sufrido mucho con la expedición del Almirante Missiesy en las Antillas: el que hacíamos en Terranova y el norte de América se ve ya molestado por los cruceros del enemigo, sin que sepamos sobre que parte del comercio y del Imperio Británico descargarán sus golpes las escuadras combinadas ${ }^{9}$. Sin embargo,

Ibidem, p. 189.

Gaceta de Madrid (2-7-1805), p. 567. 
este texto no tenía como única función la afirmación de la posesión de una fuerza naval que en la practica no existía, así como el miedo y postración de los ingleses ante la misma, sino que a su vez incluía una serie de referencias a la posible posición geográfica de la Escuadra Combinada, basada en las propias sospechas inglesas, que convenientemente recortadas adquirían una dimensión muy diferente.

La primera de ellas aparece tomada de una fuente londinense fechada el 26 de mayo, según la cual, el propio Nelson en sus pliegos manifiesta su opinión particular de que las escuadras combinadas se dirijan a Irlanda, por cuya causa se había puesto en estado de estorbar sus intentos. No se dice la fecha que tienen estos pliegos. Es grande la inquietud que ha causado en Irlanda esta noticia ... ${ }^{10}$. La intencionalidad de la composición del texto es evidente si consideramos que pocos párrafos después se cita una fuente procedente de la propia Dublín y fechada un día antes de la ya mencionada, en la que se hace referencia a reuniones de ciudadanos descontentos: En general se espera en Irlanda una explosión próxima ${ }^{11}$. En nuestra opinión, no se trata tan sólo de una maniobra de despiste respecto a la verdadera posición geográfica de la Escuadra Combinada, sino que, a su vez, la unión de ambas afirmaciones presentaría la posible intervención de franceses y españoles sobre el área irlandesa como un acto de liberación de estas tierras frente al yugo de la corona inglesa, y a la vez manifiesta la existencia de puntos débiles del Imperio Británico en la propia Inglaterra. Finalmente, el ejercicio de confusión y la presunción de fuerza se completan colofonando el texto con la afirmación, fechada también en 24 de mayo, en Cork, de que ayer mañana llegó un correo con una orden al comandante del puerto para que aprontase e hiciese salir cuanto antes todas las embarcaciones armadas. Luego que se supo esta orden reinó en la ciudad la mayor inquietud y terror, pues estas disposiciones hacían creer que el enemigo se había mostrado con fuerzas por aquella parte ${ }^{12}$.

La siguiente comunicación realizada por la Gaceta parece basarse en fuentes exclusivamente londinenses, versando casi en su totalidad sobre el estado de la armada inglesa, e insinuando claramente la superioridad de las fuerzas franco-españolas. Se trata de una reseña de parte de una de las sesiones de la Cámara de los Comunes. En lo que se refiere a la Escuadra Combinada, el texto habla por sí mismo: ...Y finalmente dijo Lord Darnley: ¿adonde nos ha conducido este sistema de profusión? ¿adonde nos ha conducido el Almirantazgo actual con sus necedades? ¿a ver salir de los puertos de Francia escuadras formidables sin que las nuestras puedan oponerse a su salida, a su marcha, y a sus operaciones: a ver un enemigo encarnizado en nuestra destrucción, salir y surcar como en triunfo aquellos mares, que creíamos tan bien protegidos por nuestra tan celebrada marina, y escaparse de sus puertos, que creíamos bien cerrados con nuestros bloqueos o ver acometer y saquear nuestras posesiones de las indias occidentales? ${ }^{13}$.

Resulta obvio considerar que tales afirmaciones en cuanto al estado comparativo entre la marina inglesa y la francesa resultan bastante exageradas, sin embargo, para una correcta interpretación de dicho texto, hemos de apartar un tanto los datos históricos de que hoy disponemos y considerar de forma aislada los que respecto a la Escuadra Combinada podían tener los ingleses durante los meses previos a la batalla. Es un hecho que los británicos desconocían las deficiencias que presentaban los buques de la Armada española, prueba de ello era por ejemplo la gran consideración que tenían hacia el Santísima Trinidad, puesta de manifiesto en el empeño del propio Nelson en la captura de dicho buque, a pesar de sus bajas cualidades de maniobrabilidad

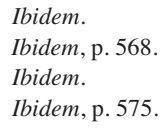


y navegación. Al respecto, la impresión que debía causar la Escuadra, con su magnificencia, por una parte, y sus deficiencias, por otra, sería bastante contradictoria. En cuanto a ello, resultan muy reveladoras las misivas del propio Villeneuve, que en unos momentos realiza afirmaciones tales como: Ha llegado la ocasión de decirlo, nunca salieron a la mar buques tan malos; esta es la causa principal de mis desgracias... mientras que en otros afirma: Causa pena ver unos navios tan hermosos y tan fuertes, tripulados por pastores y pordioseros... ${ }^{14}$

Por otra parte, alguna unidad de la Armada, concretamente El Rayo, contaba durante el año 1805 con un total de 56 años de servicio, lo que sitúa su construcción en el año 1749 , con lo que se trata de una de las unidades construidas dentro de la política de impulso dada a la marina por el Marqués de la Ensenada. La supuesta participación del gobierno inglés en la conspiración que se produjo en la Corte de Madrid y culminó con la sustitución del primer ministro español por Ricardo Wall, así como la famosa frase no se construirán mas barcos, nos lleva a la consideración de que los ingleses no contasen con la existencia de unidades construidas en dicha época, ya que precisamente habían participado en la conspiración antiensenadista para suprimir el potencial peligro de la mejora en cantidad y calidad de la marina de guerra hispana, propiciada por el marqués ${ }^{15}$.

En cuanto a la Marina francesa, ésta había sucumbido en Abukir ante los ingleses, si bien la nación gala había llevado a cabo una fuerte política de construcción en los años previos a la batalla, presentando una fuerza respetable, que unida a la española, cuyas debilidades desconocían los ingleses, podía perfectamente dar la impresión en los momentos iniciales de escuadras formidables o enemigo encarnizado.

A la hora de tratar las características de las escuadras que se enfrentaron en aguas de Cabo Trafalgar, en la mayor parte de las ocasiones se ha hecho especial hincapié en la superioridad numérica que presentaba la Escuadra Combinada. Sin embargo, los mencionados aspectos eran tanto o más importantes, y fueron los que en realidad motivaron que el grueso de la Armada Real inglesa, al mando del mejor de sus almirantes, se lanzase en persecución de una escuadra cuya potencia teórica era muy superior a la práctica. Al respecto, hemos de tener en cuenta que el destino de la Escuadra Combinada era ser perseguida por la flota inglesa, con lo que debía plantear una amenaza suficientemente fuerte como para que los británicos se decidiesen a desguarnecer el Canal de la Mancha. A falta de nuevas investigaciones sobre el particular, creemos muy probable que los velados alardes de fuerza de la Escuadra Combinada que se aprecian en la Gaceta de Madrid se encuentren encuadrados en esta dinámica. Al respecto, hemos de considerar que para Napoleón, artífice final de los planes y movimientos de la escuadra, la utilidad de ésta se reducía netamente a controlar el paso de Calais durante el corto espacio de tiempo suficiente para que sus tropas desembarcasen en la costa inglesa. Valga citar su célebre frase en la cual afirmaba que dominando seis horas el Canal de la Mancha, se haría con el control mundial ${ }^{16}$ : ése era el objetivo final.

Sin embargo, una vez puesta en práctica toda esta parte del plan, era necesario poner en marcha el engranaje que diera lugar a la situación que el Estado francés esperaba, es decir, que se iniciara la cacería de la Escuadra Combinada por parte de la Armada inglesa, facilitando así el desembarco en Gran Bretaña por parte del ejército napoleónico. Desde la salida de la Escuadra de Cádiz rumbo a las Antillas, todas las especulaciones sobre su posición se habían situado alrededor de las Islas Británicas, es decir, el punto plausible situado más al norte, con lo que se

14 MÁRQUEZ CARMONA, L.: Trafalgar y el pescador de náufragos. Cádiz, Publicaciones del Sur, 2005, pp. 29-35.

15 TÉLLEZ ALARCIA, D.: "El caballero Don Ricardo Wall y la conspiración antiensenadista", en Ministros de Fernando VI. Córdoba, Universidad de Córdoba, 2002, p. 124.

16 ADKINS, R.: Trafalgar: the biography of a battle. Londres, Ed. Little, Brown, 2004, p. 1. 
esperaría dar la máxima ventaja posible en la singladura a la Combinada respecto a la Marina inglesa. Ahora llegaba el momento de enviar a los ingleses a las Antillas, mientras la Escuadra Combinada iniciaba la singladura al Norte que debía llevarla primero a cabo Finisterre, Brest y después al Canal de la Mancha.

Respecto al ardid utilizado para mover a Nelson desde el Mediterráneo hasta las Antillas, de forma indirecta la Gaceta nos da cuenta del mismo: Los pliegos cogidos a bordo del paquebot español Etruria parecen escritos al objeto de engañarnos. En efecto parece absurdo que el 29 de Abril se hiciese a la vela este buque para disponer los preparativos necesarios para el arribo de una escuadra que había salido el 10 del mismo mes. No sabemos positivamente el contenido de estos pliegos; pero se cree que anuncian que las escuadras combinadas se dirigían a las Indias Occidentales. Tal vez puede ser política de los franceses inspirarnos desconfianza de unos pliegos auténticos, cuando nos han engañado tantas veces con avisos falsos.

Se ha recibido una carta de Lord Nelson, con fecha en alta mar tres días después de su salida de la bahía de Lagos el 11 de Mayo. Iba este almirante en seguimiento de las escuadras combinadas $^{17}$.

Sin embargo, a pesar de esta última afirmación, si bien es posible que el propio Nelson se encontrase relativamente seguro de que la dirección adecuada para dar con la Escuadra Combinada era poner proa a las Antillas, parece ser que el Gobierno británico no concedía aun suficiente credibilidad a los datos de que disponía para considerar que la flota que había salido de Cádiz entre el 9 y el 10 de Abril era la Combinada, como se desprende de afirmaciones vertidas en el propio Parlamento inglés: En poco tiempo ha hecho la Francia grandes progresos: ha burlado, con sus planes bien combinados, la previsión de nuestro gobierno, y hecho expediciones considerables, perjudiciales a nuestro gobierno, y vergonzosas para nuestra nación: y no es extraordinario que el 20 de Junio ignoremos aun el destino de una expedición que salió de Cádiz en 9 de Abril. En cuanto al destino de las escuadras combinadas, es de opinión que la Jamaica es su destino principal ${ }^{18}$.

De esta forma, haciendo una breve recapitulación de fechas, sabemos que la Escuadra Combinada inició su singladura atlántica durante la noche entre el 9 y el 10 de Abril, mientras Nelson la esperaba en el Mediterráneo y la Gaceta la situaba en aguas próximas a Irlanda del Norte. El 29 de dicho mes zarpó el Etruria con los pliegos, que al margen de la consideración que los ingleses tuviesen sobre su verosimilitud eran, en realidad, la única fuente veraz con que contaban respecto al destino de la Escuadra Combinada. La singladura de la Escuadra se prolongó alrededor de treinta y cinco días, ya que los distintos navíos llegaron a Fort Royal (Martinica) entre el 14 y el 16, y finalmente, el 11 de Mayo zarpó Nelson de la Bahía de Lagos (sur de Portugal) hacia el otro lado del Atlántico en busca de la Escuadra Combinada, posiblemente tras confirmar la veracidad de los pliegos del Etruria mediante otras fuentes, algunas de ellas citadas una vez mas por la Gaceta, según la cual (sin aportar la fecha concreta, pero con posterioridad al 28 de abril) ayer se recibió en la ciudad una carta de Bristol, en que se anuncia que el Swift acaba de llegar de las indias Occidentales con la noticia de que las escuadras combinadas se habían visto a la altura de la Barbada el 28 de Abril. No se ha dado crédito a esta noticia; porque desde el tiempo de su salida hasta el 28 de Abril no han tenido tiempo de llegar a las Indias Occidentales ${ }^{19}$. Considerando a su vez esta última afirmación, resulta plausible la posibilidad de que a su vez

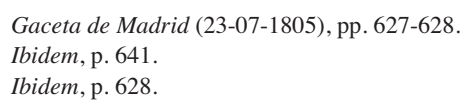


los ingleses tampoco tuviesen una idea concreta acerca de la fecha de partida de la Escuadra Combinada.

De esta manera, la maquinaria de distracción había funcionado perfectamente, otorgando un margen total de 25 días entre la llegada de la Escuadra a las Antillas y la salida de Nelson hacia este mismo punto, tiempo más que suficiente para que la Escuadra pudiese llevar a cabo las maniobras necesarias en el Caribe y se encontrase a tiempo en el Canal de la Mancha.

Durante la primera quincena de julio, la primera fase de la operación se consideraba ya un éxito por parte de los gobiernos francés y español, ya que el 14 de julio, en vísperas del inicio de la singladura hacia el norte, el gobierno francés hacía pública una misiva del Almirante Villeneuve, despejándose oficialmente ya todas las dudas, en la que este explicaba las circunstancias del inicio de la derrota hacia las Antillas, así como el verdadero rumbo de la Escuadra Combinada. La publicación de este texto hemos de verla como colofón a la operación de distracción llevada a cabo hasta el momento. Ahora Nelson se encontraba en las Antillas y la Combinada, por otra parte, dispuesta a partir de nuevo, de manera que lo más conveniente era dar a entender, una vez mas veladamente, que el teatro de operaciones de esta escuadra era el Caribe, de forma que Nelson la buscase en dicho archipiélago el máximo tiempo posible, permitiendo así el cumplimiento de los objetivos fijados para el Canal de la Mancha. Al respecto, la Gaceta recoge que en su carta Villeneuve da cuenta al ministro que desde su salida de Tolón, el 30 de Marzo, no había avistado sino dos fragatas inglesas, que a larga distancia le observaban, estando aun a la vista de las costas de Provenza al día siguiente de su salida, y un buque Raguseo, que dijo que el 25 estaba la escuadra inglesa en las aguas de Cerdeña. Que el 7 de Abril, hallándose delante de Cartagena, y viendo que había navios armados, envió una lancha para saber noticias de mar, y ofrecer sus servicios, y la protección de la escuadra a los navios de S.M.C. que quisiesen unirse a ella; pero el comandante español le hizo saber que en el plan general de las operaciones combinadas de las dos cortes tenia otro destino, y hacía parte de otra escuadra que la que mandaba Villeneuve. El 9 al amanecer descubrió la roca de Gibraltar, y dirigiéndose hacia el estrecho con las precauciones necesarias, hicieron señal las dos fragatas descubridoras, que huían delante de ellas un navio y dos fragatas inglesas. Así de las baterías de Gibraltar como los buques que iban huyendo, no cesaron en mucho tiempo de tirar cañonazos de aviso. A las 4 de la tarde hicieron las dos fragatas señal de avistar 11 bajeles, de los cuales 6 eran navios de guerra; y a corto rato avisaron que el enemigo huía; pero como la escuadra francesa estaba muy distante, y ya era tarde, no pudo seguir a la inglesa. La misma noche salió de Cádiz la escuadra española, a las órdenes del teniente general Don Federico Gravina, y unida a la Francesa principiaron a hacerse a la vela a las 2 de la mañana del día 10 con rumbo al O. Desde aquel momento la Escuadra Combinada no tuvo mas novedad que algunas calmas y vientos contrarios. El 9 de Mayo, hallándose a la altura prescrita por las instrucciones, y en virtud a lo que en ellas se prevenía, entregó Villeneuve a Gravina sus pliegos, y haciéndo una señal se pusieron a sus órdenes 6 navios de S.M.C., y 2 fragatas, y 2 briks de S.M.I. cuya división se perdió de vista con la noche caminando a su destino. Las fragatas Hortensia y Hermione, que iban muy adelante, volvieron a reunirse con Villeneuve el 13, conduciendo apresada a la corbeta inglesa la Cyane, de 24 cañones y 125 hombres de tripulación, mandada por el capitán Cadogant. El mismo día descubrieron la Martinica, y el 14 arribó a aquella isla el vicealmirante Villeneuve con la escuadra de su mando, y con dos navios y una fragata españoles que se les habían juntado. Elogia Villeneuve a varios oficiales de su escuadra, y particularmente al General Gravina por su actividad, su celo y buena armonía; y en el momento en que escribía, el día 17, dice: Estoy haciendo aguada; he encontrado la colonia abundantemente provista de víveres. El general Lauriston parte para la Guadalupe, a fin de reunir todos los transportes que pueda. Según las noticias que he tenido pienso que el general Gravina no encontrará ningún 
obstáculo en su expedición, e inmediatamente que se me reúna, que creo será pronto, no perderé un instante en ir a mi destino ${ }^{20}$.

\section{EL BRILLO DE UNA DUDOSA VICTORIA: EL CABO FINISTERRE}

Tras el exitoso desarrollo de las operaciones de distracción llevadas a cabo durante la singladura de la Escuadra hacia el Caribe, en dicho archipiélago la Escuadra Combinada llevó a cabo acciones de pequeño calado tales como la toma del Islote del Diamante ${ }^{21}$ (hasta ese momento en manos británicas) o la captura de un convoy británico en las proximidades de Barbada el 8 de Junio $^{22}$.

El regreso había de realizarse tomando como destino inicial El Ferrol, puerto en que debían unirse a la Combinada los navíos españoles que se encontrasen armados, tras lo cual había de ponerse sin pérdida de tiempo rumbo a Brest, iniciando así la segunda fase del plan napoleónico. Parece ser que durante la ruta de regreso se dieron una serie de problemas, entre los cuales destacó la falta de agua en los navíos. Al respecto, se ha considerado que una de las causas de esta deficiencia era el exceso de tripulación en las distintas unidades, si bien este problema no se había presentado durante el recorrido de ida. Llegados a este punto, no hemos de olvidar que a la llegada de los pliegos Villeneuve y las unidades que habían permanecido con él en Port Royal se encontraban haciendo aguada, mientras que Gravina con otro grupo se había dirigido al norte. Al respecto, la premura de las órdenes imperiales, así como la frase ...e inmediatamente que se me reúna, que creo será pronto, no perderé un instante en ir a mi destino, nos permiten considerar que las unidades españolas no tuvieron tiempo suficiente para hacer aguada, lo cual agravaba el problema del exceso de tripulación.

A pesar de todo, la Escuadra Combinada se encontraba ya en las proximidades de $\mathrm{El} \mathrm{Fe}$ rrol el 20 de julio, con la intención de solucionar los problemas derivados de la singladura de vuelta y continuar con el plan previsto. Así, el día 22 la escuadra se encontraba doblando el Cabo Finisterre, pero en sus inmediaciones se encontró con la escuadra británica de Robert Calder, produciéndose el consecuente enfrentamiento. Mucho se ha escrito acerca de los pormenores de dicho combate, así como de las consecuencias del mismo de cara al futuro enfrentamiento de Trafalgar (navíos averiados, capturados, etc.). Sin embargo, respecto al tema que nos incumbe, se trata de un importante hito, ya que desde este momento se rompe la política informativa que hasta entonces habían llevado impecablemente los gobiernos francés y español. Nelson pronto conocería la ubicación y rumbo de la Escuadra Combinada, así como sus características y parte de sus deficiencias. Sin embargo, lo más importante de todo ello era que el descubrimiento de la Combinada al norte de la Península Ibérica convertía el plan napoleónico en previsible, y, por tanto, en caso de llevarse a cabo, con muchas menos posibilidades de éxito.

Ante esto, sólo quedaba una salida en cuanto a política informativa se refería: presentar el combate como una victoria de la Escuadra Combinada y, por supuesto, como una actuación prevista dentro de los planes de combate.

Se inicia desde este momento un bloque informativo dominado por las referencias directas, inaugurado a su vez por la publicación de una carta de Gravina a Godoy relatando el enfrentamiento de Cabo Finisterre:




Excmo. Sr. Muy Sr. Mío: demorado el Cabo Finisterre al S. E., distancia de 25 leguas, el día 22 de Julio, navegaba la Escuadra Combinada con viento ONO en formación de tres columnas al rumbo del E1/4SE., cubiertos los horizontes de niebla espesa...Cubierto ya el último navio de la retaguardia, rompió el fuego a las cinco menos cuarto el navío Argonauta, en que tengo arbolada mi insignia, con la vanguardia inglesa... Al amanecer del día 23 en la descubierta, aunque con niebla, contamos nos faltaban 2 navíos de la escuadra, y que estos eran el Firme y el San Rafael... ${ }^{23}$

No será ésta la única referencia basada en fuentes españolas que haga la Gaceta al combate de Cabo Finisterre. Posteriormente, se llevará a cabo la publicación de varios extractos de correspondencia de Gravina, en los que se destaca especialmente el empeño de la Escuadra Combinada en la persecución posterior al combate: Durante este día y el 24 se le dio caza, pero infructuosamente, porque siempre maniobró la escuadra inglesa para evitar el encuentro; no dejando duda de que su ánimo era no volver al combate... ${ }^{24}$

La imagen de victoria dada al combate de Cabo Finisterre se consolida finalmente extractando la relación de lo sucedido en el mismo número de la Gaceta según la correspondencia de Villeneuve. Dicho texto coincide a grandes rasgos con la versión de Gravina, si bien cargando más las tintas sobre el buen balance final para la Escuadra Combinada, así como el papel de las unidades españolas. Así, en el extracto publicado se reseña: Nosotros tirábamos a la luz del fuego del enemigo casi siempre sin percibirlo: solamente al fin del combate, en un corto rato de claridad, pude ver a sotavento de la línea un navío con bandera española, que se mantenía ciñendo el viento con las velas mayores y las gavias arriadas, cerca del cual estaban dos navíos enemigos, el uno enteramente desmantelado, y el otro de tres puentes falto del mastelero de Gavia. El navio desmantelado apareció en una grande confusión, y que apenas bastaban todas sus bombas. Finalmente, tras afirmar que, según testimonio de uno de sus capitanes, la Escuadra Combinada había hundido durante la operación un navío inglés, culmina su exposición afirmando que este combate, sin embargo, ha sido honorífico a las dos naciones; y sin la niebla tan espesa, que continúa aun, y que ha favorecido los movimientos y la retirada del enemigo, no se hubiera escapado a nuestros esfuerzos, ni de un combate decisivo ${ }^{25}$.

Sin embargo, como veremos mas adelante, no terminó aquí el bloque informativo que la Gaceta destinó a la presentación de la acción de Cabo Finisterre como una victoria. Por razones sobre las que profundizaremos en el siguiente epígrafe, aun en octubre, la Gaceta seguía publicando diversas informaciones acerca de dicha acción bélica, siendo la última de ellas la supuesta versión del Almirante Calder al respecto, la cual coincide a grandes rasgos con las dadas anteriormente, si bien con ligeras salvedades, que desmienten la supuesta victoria franco-española:... avisté las escuadras combinadas de Francia y España, que se componían de 20 navios de línea, 3 navíos armados en urcas de unos 50 cañones, 5 fragatas y 3 bergantines. Las fuerzas de mi mando consistían en 15 navíos de línea, dos fragatas, una balandra y un lugre. Inmediatamente marché hacia el enemigo... empeñándome en un combate, que duró mas de 4 horas; en cuyo tiempo me pareció necesario poner la escuadra en facha para asegurar los dos navíos apresados. Para no mostrarnos excesivamente reiterativos, tan sólo transcribimos estas frases extractadas del texto de Calder, a las cuales, siguiendo con la política informativa llevada a cabo en este bloque hasta el momento, aparecieron asociadas las ya conocidas "notas del monitor": Es cierto que en el combate hubo 14 navíos franceses y 6 españoles; pero no lo es que hubiese 3 navios de 50. El Almirante Calder combiene en que

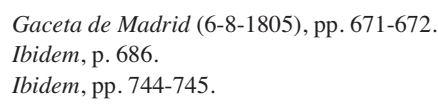


el cesó primero el combate. La razón que da para ello, de asegurar los 2 navíos españoles apresados, está desmentida con lo que se sabe de que éstos cayeron en poder del enemigo después del combate y durante la noche, porque ya no podían maniobrar, acercado a sotavento. La verdadera razón es que ha tenido 4 navíos desarbolados. Tampoco dice el Almirante Calder que el Windsor-Castle y el Malta estaban tan maltratados, que con gran trabajo han podido arribar a las costas de Inglaterra; de modo que su escuadra se halla reducida a 13 navíos ${ }^{26}$.

Ésta era la realidad presentada por la Gaceta a la opinión pública. Sin embargo, en este caso no se trata de realidades mas o menos ficticias utilizadas para llevar a cabo operaciones encubiertas, sino mas bien del maquillaje algo tendencioso de una serie de acciones de combate cuyo resultado podía ser interpretado de múltiples maneras en función de los intereses del interprete. Así, según la documentación estudiada por algunos especialistas en la materia queda claro que el abandono del combate por parte de Calder, así como su posterior persecución por parte de la Combinada fue un hecho: La intención final era provocar una acción decisiva contra Calder, ahora que sus unidades se encontraban en igual o peor estado que las franco-españolas. Esto es, Villeneuve no rehuyó el combate, ni mucho menos Gravina, midiendo además las posibilidades entre su propia flota y la Flota inglesa para una nueva refriega. No obstante, y como ya hemos dicho, Calder maniobró permanentemente al objeto de evitar un nuevo enfrentamiento ${ }^{27}$. Sin embargo, sí resulta un hecho que en las relaciones que publica la Gaceta se encubre en lo posible el estado de las unidades de la combinada de resultas del mencionado combate. Además de los navíos de vanguardia, sabemos que el resto de los buques de la flota combinada, en especial los de centro a vanguardia, sufrieron también enormes averías, hecho que debemos mantener en la memoria ante la clave decisión posterior de Villeneuve de virar hacia Cádiz en lugar de hacia Brest. Para el caso del Argonauta, éste quedó sin palos de mesana y sin jarcias, así como sin gran parte del velamen mayor, a lo que se habrían de añadir 21 balazos de cañón en costados y cubierta. En lo referente al Terrible, se hallaba destruido prácticamente todo el velamen, incidiendo en la maniobrabilidad del barco, así como desmontados dos obuses y con varios impactos de bala en cubierta. En los casos del España y del América, la situación era muy similar: sin velamen, sin jarcias, destrozado el palo de mesana y, para el caso del España, con 26 balazos de cañón sobre su castillo y cubierta. El resto de las unidades, aunque con averías de menor envergadura, se encontraba también en penosa situación de maniobra... ${ }^{28}$

Tras la acción de Finisterre, la Escuadra se dirige al puerto de Vigo en lugar de al de El Ferrol, debido a la mayor proximidad del primero, así como a los daños sufridos en el combate, el alto número de heridos y el resto de las necesidades materiales de la flota ${ }^{29}$, si bien permanecieron corto espacio de tiempo en el mismo, ya que el 31 de julio los navíos que aún se encontraban en condiciones de combatir abandonaban ya dicho puerto. Parece ser que, una vez puesto rumbo a El Ferrol, Gravina se adelantó a Villeneuve, el cual en esos momentos recibió órdenes directas del Emperador que prohibían a la Escuadra francesa fondear en dicho astillero, posiblemente en un intento de Napoleón de acelerar la llegada de la Combinada al Canal de la Mancha. Ante esto, Villeneuve y sus unidades fondean en La Coruña, mientras que Gravina ya se encontraba en El Ferrol a la llegada de las órdenes del Emperador. Será en estos momentos cuando la Combinada se vea reforzada por las flotas de los almirantes Gourdon y Grandallana con un total de 12 navíos de línea ${ }^{30}$.

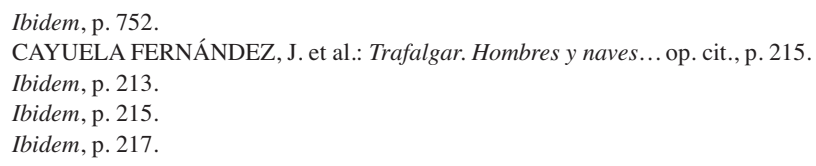




\section{HONOR Y AGONÍA: EL ÚLTIMO DESTELLO DE LA ARMADA}

Llegados a este punto, se produce un acontecimiento que constituirá un auténtico eje en cuanto a las operaciones de la Escuadra Combinada, estableciendo claramente un antes y un después. Se trata del inicio del movimiento de la flota hacia un punto no contemplado en el plan de operaciones: Cádiz. Este hecho, denominado por buena cantidad de autores el "error Villeneuve", ha sido achacado por la historiografía especializada a diversos factores, oscilando desde la opinión tradicional, que tachaba a Villeneuve de cobarde y hacía de su miedo la principal razón para virar hacia Cádiz, hasta las nuevas líneas que apuntan a factores tales como la necesidad de refuerzos, el desconocimiento de los nuevos planes napoleónicos en Centroeuropa, la descoordinación entre las distintas escuadras francesas y españolas, etc.

No entraremos aquí en dirimir tales cuestiones, entre otras cosas porque consideramos que en la actualidad carecemos de datos suficientes para llegar a una tesis concluyente, mas allá de la recientemente puesta de manifiesto que aboga por que la decisión vino dada por un cúmulo de circunstancias que tuvieron lugar en el Cantábrico durante un corto espacio de tiempo tras el enfrentamiento con Calder. Sin embargo, reseñaremos algunos acontecimientos que sin duda contribuyeron a la toma de tal decisión:

En primer lugar, tras el combate, Villeneuve pretende dirigirse a El Ferrol, con objeto de utilizar dicho astillero para la reparación integral de sus naves, pero recibe la prohibición tajante del Emperador de fondear allí. En el momento de dictar esas órdenes, Napoleón ignoraba completamente el enfrentamiento contra Calder y el estado de la flota combinada ${ }^{31}$, cosa que a su vez influyó muy negativamente en la moral del almirante ${ }^{32}$.

En segundo lugar, además de las escuadras de Gourdon y Grandallana, la Escuadra debía ser reforzada por el contingente comandado por Allemand. Dicho hecho no se produjo, entre otras cosas, porque ambas escuadras se cruzaron y se detectaron entre sí, pero no se reconocieron como aliados ${ }^{33}$.

Por último, en el momento de tomar la decisión, Villeneuve desconocía totalmente los nuevos planes de Napoleón, así como la partida del grueso del ejército francés hacia el centro de Europa ${ }^{34}$.

En suma, estos hechos son una muestra de la cadena de circunstancias que se dieron en el Cantábrico, si bien en todos ellos encontramos como tónica general la falta de información, debida a los fallos en los cauces de comunicación entre el Estado y la Escuadra. De esta forma, la avalancha de acontecimientos en un corto espacio de tiempo, unida a la lentitud de los canales de comunicación, provocaron un colapso informativo, que probablemente tuvo una influencia capital en la decisión de Villeneuve de poner rumbo a Cádiz.

Llegados a este punto, podemos realizar la clasificación de los sistemas de información estatales en dos grandes grupos: primarios y secundarios. Los primarios son aquellos que articulan la actuación del aparato estatal, comunicando el órgano decisorio (en este caso el Emperador) con el ejecutor (Villeneuve), y dando lugar a la realización en la práctica de una serie de acciones y decisiones. Por otra parte, el sistema secundario depende en su funcionamiento de la efectividad del primario, siendo un sistema abierto que comunica el órgano decisorio con el exterior. La relación entre ambos sistemas se completa con un proceso de retroalimentación, cuyo ejemplo sería el caso de la singladura del Atlántico, durante la cual la información vertida al exterior

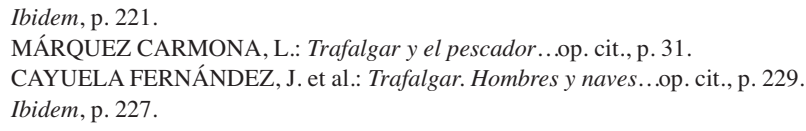


por el sistema secundario contribuye al buen funcionamiento y coordinación del primario (en el intervalo cronológico previsto, la Combinada se encontraba ya en Finisterre, mientras que Nelson aún estaba saliendo de las Antillas y tomando por añadidura rumbo hacia el sur de la Península).

Sin embargo, la estrecha relación entre ambos sistemas haría que, en caso de colapso del primario, el secundario (del que forma parte importante la Gaceta de Madrid) quede también inoperativo. Eso fue exactamente lo que ocurrió a lo largo del verano de 1805. Tras el combate contra la escuadra inglesa de Calder, la Gaceta no reseña ningún tipo de información acerca de la Escuadra Combinada, limitándose a reiterativas relaciones del combate de Finisterre, hasta el punto de que tras la última que hemos mencionado en el epígrafe anterior, aun el 6 de septiembre, la Gaceta todavía seguía publicando relaciones de la acción bélica del 22 de julio ${ }^{35}$. Por otra parte, no se trataba de la primera vez que ante determinadas situaciones la Gaceta guardaba el más absoluto mutismo. Un ejemplo de ello lo tenemos en el año 1794, durante el cual Gravina participó en la defensa de Rosas. Al respecto, Valdés le escribiría poco después: No se le de a usted cuidado de que no hable de la defensa de rosas la Gaceta, ni que el diario puesto en la última haga tan poca mención de la marina ... ${ }^{36}$

El colapso del sistema informativo franco-español, así como la consabida decisión de Villeneuve de poner rumbo a Cádiz, habían iniciado una reacción en cadena que aún no había concluido. Ya con anterioridad al 13 de agosto (día de la partida de la Combinada hacia Cádiz), los servicios de inteligencia franceses habían avisado a Napoleón de un movimiento masivo de tropas austriacas y rusas hacia el Oeste, cuyo probable objetivo era la retaguardia francesa. Ante esto, Napoleón inició los preparativos para afrontar el choque militar. No entraremos aquí en el análisis de los efectos del cambio de escenario de la guerra dentro de las campañas napoleónicas, sin embargo, sí incidiremos en que esta serie de acontecimientos, debido a la incertidumbre que causaron en todos los participantes en la contienda, situarían el culmen del colapso informativo entre los días 13 y 19 de agosto, ya que la entrada en Cádiz de la Combinada el día 20 de agosto aceleró el resto de las decisiones: Napoleón movilizaría a todos los cuerpos de ejército sitos en Boulogne a través de Alemania para establecer una contraofensiva lo mas rápida posible sobre las fronteras del Este $e^{37}$.

De esta forma, no sería descabellado considerar que entre el 13 y 19 de agosto ninguna de las naciones implicadas en la guerra conocía la posición ni rumbo de la Escuadra Combinada, hipótesis que queda reforzada si consideramos, que según el Morning Chronicle, el 14 de agosto, en Inglaterra, aún se consideraba prácticamente seguro un intento de desembarco en sus costas, reseñando que los diarios de París y Holanda... hablan del aumento de los preparativos, y todos convienen en excitar en nosotros inquietudes; ¿pero olvidamos ya de que mas de cien veces han repetido lo mismo? ¿Tienen los Franceses en el día mas tropas en Holanda? ¿Han aumentado sus campamentos en Boloña? Es ciertamente muy probable que Bonaparte intente el desembarco antes de terminar la guerra... ${ }^{38}$

Finalmente, sabemos que Villeneuve desconocía los movimientos de tropas que se estaban dando en Centroeuropa, de la misma manera que Napoleón desconocía, con anterioridad a la llegada de la Combinada a Cádiz, los pormenores del combate de Finisterre, así como las consecuencias derivadas del mismo. En estos momentos de incertidumbre y falta de información, ambos tomaron sus decisiones como militares que eran, y lo hicieron según unos parámetros muy

\footnotetext{
35 En este caso se trata de una misiva de Villeneuve a Decrés relatando el particular someramente, coincidiendo con la versión dada hasta el momento.

36 ALCALÁ GALIANO, P.: El combate de Trafalgar. Madrid, Imprenta del Depósito Hidrográfico, 1909 , p. 649.

37 CAYUELA FERNÁNDEZ, J. et al.: Trafalgar. Hombres y naves... p. 247.

38 Gaceta de Madrid (10-09-1805), p. 769.
} 
similares: uno apuró el tiempo al máximo, considerando que el almirante llegaría a tiempo al Canal de la Mancha, el otro se dirigió al sur en busca de refuerzos suponiendo que llegaría a tiempo a su destino final. La decepción que sufrieron a partir del 20 de agosto debió tener connotaciones muy parecidas.

Respecto a la estancia de la Escuadra en Cádiz, sabemos que ésta se desarrolló sin ningún tipo de incidentes, a pesar de la mala situación que en aquellos momentos vivía la ciudad, fruto a su vez de recientes epidemias, así como de falta de trigo, a pesar de lo cual, la Escuadra pudo abastecerse ${ }^{39}$, frente a opiniones poco fundamentadas que afirman que se produjeron continuos altercados entre marineros franceses y españoles, así como la existencia de cierta hostilidad por parte de Gravina hacia Villeneuve ${ }^{40}$. Este ultimo extremo choca con todas las pruebas documentales existentes al respecto y que sería muy largo citar, si bien, ya en Vigo, escribió de su puño y letra el almirante francés: En la desgracia no se tienen amigos: cuento afortunadamente con uno, el General Gravina; el lamenta y toma parte muy viva en mi situación... ${ }^{41}$

A pesar de ello, el colapso informativo no comenzó a disiparse hasta bien entrado el mes de octubre, momento en que la Gaceta vuelve a publicar noticias sobre la Escuadra Combinada, si bien todas ellas indirectas y procedentes de Inglaterra, en las que finalmente se confirmaba la entrada de la Escuadra Combinada en Cádiz. Sin embargo, se observa un total mutismo informativo por parte de las autoridades tanto francesas como españolas, llegando a un tratamiento tan aséptico de tales avisos que da la sensación de tratarse de noticias que en nada incumbían a España $^{42}$.

Finalmente, la Gaceta no pudo omitir lo inevitable, la publicación de los acontecimientos acaecidos en las proximidades de Cabo Trafalgar el 21 de octubre, y, por tanto, la asunción de cara a la opinión pública de la derrota de la Escuadra Combinada. La forma escogida en esta ocasión presenta ciertas analogías con la utilizada para Cabo Finisterre. Esta vez se llevó a cabo la publicación de la misiva de Escaño a Godoy informando de lo sucedido: La situación en que está el teniente General D. Federico Gravina de resultas de un balazo de metralla que al fin de la acción de ayer recibió en su brazo izquierdo, no le permite dar a VE noticia de este combate sangriento; y aunque yo he tenido la fortuna de derramar mi sangre por el honor de las armas del rey nuestro amo recibiendo otro en la pierna, hallándome sin embargo menos agravado que el bizarro y dignísimo general en jefe, a quien SM por la justa confianza que le merece había conferido el mando de su Armada, me encuentro en la triste pero necesaria obligación de desempeñar el encargo de poner en noticia de VE que nuestros esfuerzos y el heroico abandono de nuestros días, no han alcanzado a evitar una pérdida que sería considerable si no estuviésemos tan firmemente convencidos de que nada nos quedó que hacer, y que por consecuencia se salvó el honor...43

Tras la publicación de este texto, y hasta diciembre de 1805 , se observa el progresivo reajuste del sistema informativo, que se convertirá en el colofón de las acciones de la Gaceta en cuanto a las operaciones de la Escuadra Combinada. Las informaciones publicadas evolucionarán desde la atención preferente a los hechos navales, cuyo máximo exponente será la reseña de la acción llevada a cabo por los navíos supervivientes de la Escuadra española, que finalmente culminó con el represamiento de varios buques en manos inglesas, entre los que se encontraba

\footnotetext{
39 RAMOS SANTANA, A.: “Cádiz y el combate naval de Trafalgar”, en Trafalgar y el mundo Atlántico. Madrid, Marcial Pons, 2004, pp. 321-323.

40 ADKINS, R.: Trafalgar: the biography of a battle... op.cit., p. 58.

41 MÁRQUEZ CARMONA, L.: Trafalgar y el pescador... op.cit., p. 30.

42 Gaceta de Madrid (10-10-1805), p. 832.

43 Ibidem, pp. 953-955.
} 
el Santa Ana, con un porte de 120 cañones $^{44}$, hasta la minimización de los efectos de la derrota, pasando por la exaltación del comportamiento, tanto a nivel militar como humano, de las tropas españolas. Hemos situado el inicio de la reestructuración del sistema informativo en la publicación de la acción del 23 de octubre debido a que en dicha narración ya se aprecia una cierta tendenciosidad, síntoma, una vez mas, de la existencia de directrices de información. Dicha tendenciosidad se refleja, por ejemplo, en la omisión del naufragio de varios de los navíos que salieron con objeto de represar los buques en manos inglesas. Tal fue el caso, entre otros, del navío Rayo, poniendo así fin a sus cincuenta y seis años de servicio en la Armada Española tras naufragar el 26 de octubre de 1805 en la costa de Arenas Gordas (Huelva), antigua "Provincia Marítima de Sanlúcar de Barrameda", entre las torres vigías de Zalabar y Carbonera ${ }^{45}$.

\section{CONCLUSIONES}

En conclusión, podemos decir que la información dada por la Gaceta de Madrid acerca del conjunto de operaciones llevadas a cabo por la Escuadra Combinada durante la campaña de 1805 responde a un incipiente modelo de información y control de la opinión pública por parte del Estado. No se trata, pues, de un sistema planificado ex-profeso como complemento informativo a los planes bélicos del momento, sino que es el fruto de una larga evolución en la que la utilización del lenguaje escrito de una forma determinada contribuye a la presentación ideológicamente orientada de la realidad.

Este sistema, a su vez, se caracteriza por la utilización de determinados recursos, ya ideados siglos antes, destinados a reforzar la verosimilitud de la narración realizada, tales como la utilización de referencias directas o indirectas en función al momento y realidad concreta a presentar, la atribución de autoría a determinadas afirmaciones ${ }^{46}$, etc.

A su vez, los medios de información tales como la Gaceta se incluyen en el aparato mediático estatal, integrando lo que hemos denominado sistema secundario, en el cual se reflejan las distintas coyunturas por las que pasa el primario.

Finalmente, el importante papel jugado por los medios informativos en la campaña naval de 1805, así como los rápidos cambios de coyuntura que tuvieron lugar durante el desarrollo de la misma, permiten establecer una serie de momentos, clasificados en función al uso de la información por parte de los Estados contendientes, en los que se aprecia claramente la relación entre la información vertida, la asumida y finalmente los resultados prácticos.

\footnotetext{
44 Ibidem, p. 956. A pesar de que esta noticia se publicó en el mismo ejemplar de la Gaceta que la relación de la batalla por Escaño, situamos en su publicación el inicio de la reestructuración del sistema informativo, ya que la propia Gaceta reseña que esta noticia fue redactada con posterioridad al texto anterior.

45 MÁRQUEZ CARMONA, L.: Trafalgar y el pescador... p. 100.

46 Respecto al uso de estos recursos para el aumento de la verosimilitud de los textos, vs. ROMERO GOMEZ, J.A: $E l$ autor fingido (en prensa).
} 